\title{
sciforum
}

Conference Proceedings Paper

\section{Spatial and temporal variability of droughts in Estonia (1951-2015)}

\author{
Fernando Domínguez-Castro ${ }^{1, *}$, Sergio Vicente-Serrano ${ }^{1}$, Jaak Jaagus ${ }^{2}$, Makki Khorchani1 ${ }^{1}$, Peña- \\ Gallardo Marina1
}

Published: 11/11/2017

Academic Editor: Moncho Gesteira

1 Instituto Pirenaico de Ecología, IPE-CSIC; f.dominguez.castro@gmail.com, svicen@ipe.csic.es, makki.khorchani@gmail.com, marinapgallardo@ipe.csic.es

2 Institute of Ecology and Earth Sciences, University of Tartu; jaak.jaagus@ut.ee

* Correspondence: f.dominguez.castro@gmail.com, Tel.: +34- 976-369-393

\begin{abstract}
Droughts have been poorly studied in Estonia despite of the important water deficit that occurred in recent times e.g. 2002 and 2006. We have studied the influence of atmospheric indices on the spatial and temporal variability of droughts in Estonia. We have analyzed 57 monthly precipitation series and 7 atmospheric indices (NAO, EA, EATL/WRUS, SCAND, P/EU, AO and WI) during the period 1951-2015. Estonia has been regionalized in three homogeneous regions according to drought variability, i.e. western, southeastern and northern. Standardized precipitation index at timescale of 1, 3, 6, and 12 months have been computed for each region. From 1951 to 1977 dry conditions prevail. On the other hand, from 1978 to 2015 wet conditions prevail interrupted by some intense but short droughts. The main influence of atmospheric indices on drought variability is recorded with SCAND for spring and autumn (negative correlations) and with WI for winter and summer (positive correlations).
\end{abstract}

Keywords: Standardized Precipitation Index; Estonia; Atmospheric Circulation Indices.

\section{Introduction}

Although Estonia is a country with abundant water resources, severe droughts have occurred recently e.g. 2002, 2006. During these droughts important impacts can be recognizable on agriculture e.g. crop yield reduction, on society e.g. problems in water supply of small communities; or on the environment e.g. deterioration of water quality $[1,2]$.

Atmospheric indices are important drivers of European droughts [3-5] but regional studies are required to have a better understanding [6]. The precipitation anomalies in Estonia are largely controlled by atmospheric indices [7]. Nevertheless, there are not previous studies that have investigated the response of droughts to atmospheric indices in Estonia and few studies have examined this issue in regions above $55^{\circ} \mathrm{N}$ [8]. In this study we have analyzed the influence of different circulation indexes (NAO, EA, EATL/WRUS, SCAND, P/EU, AO and WI) in the occurrence of droughts on different time scales in Estonia. 
The 1st International Electronic Conference on Hydrological Cycle (CHyCle-2017), 12 - 16 November 2017; Sciforum Electronic Conference Series, Vol. 1, 2017

\section{Experiments}

\subsection{Data}

This study uses 57 monthly precipitation series during the period 1951-2015. The stations cover homogenously the Estonian territory (Figure 1). This is the largest data set used in the study of precipitation conditions in Estonia. The precipitation series have been homogenized with HOMER (HOMogenization software in R) software [9]. HOMER is a semi-automatic methodology that combines an automatic joint segmentation with a partly subjective pairwise detection [10].

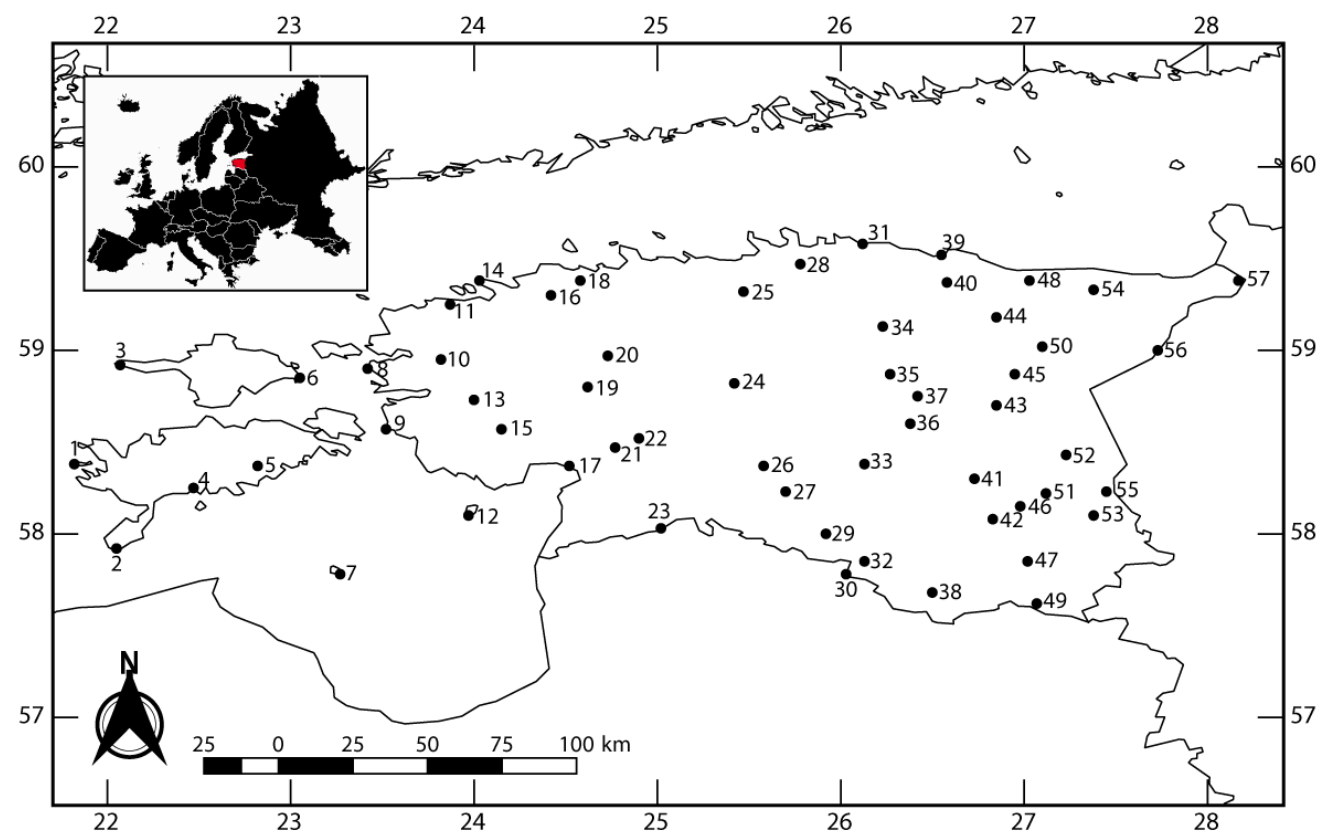

Figure 1. Location of monthly precipitation series.

Monthly NAO, EA, EATL/WRUS, SCAND, P/EU, AO from 1951 to 2015 have been obtained from the Climate Prediction Center of the NOAA (http://www.cpc.ncep.noaa.gov/data/teledoc/telecontents.shtml). These indices were computed from the rotated PCA of the $500 \mathrm{hPa}$ fields from $20^{\circ} \mathrm{N}$ poleward [11]. The Westerly Index (WI) was computed from 1951 to 2012. WI is the percentage of days per month with prevailing westerly winds over the English Channel $\left([-10,5]^{\circ} \mathrm{E},[48,52]^{\circ} \mathrm{N}\right)[12]$.

\subsection{Methods}

We have analyzed the spatial variability of precipitation using principal component analysis (PCA) in the $\mathrm{S}$ mode for the 57 monthly precipitation series. Taking into account the PCs loadings, we have computed one regional precipitation series for each PC. Moreover a country series has been calculated based on Thiessen polygons.

We have computed 1, 3, 6 and 12 months SPI time scale for regional and country series to determine the drought severity. The SPI is a robust drought index that only requires precipitation data to be computed, and allows to represent the multi-scalar drought character being computed with different time windows [13].

Pearson's correlation coefficients between SPI series and the 7 circulation indices have been computed, at different time scales, to evaluate the influence of the atmospheric indices on droughts. 
The 1st International Electronic Conference on Hydrological Cycle (CHyCle-2017), 12 - 16 November 2017; Sciforum Electronic Conference Series, Vol. 1, 2017

\section{Results}

\subsection{Precipitation spatial variability}

The precipitation PCA analysis has detected three principal components that explain the $33.6 \%$, $31.2 \%, 18.9 \%$ of the variance respectively (Figure 2 ). The first PC shows a clear gradient west to east with the highest loadings in the western islands (Saaremaa, Hiiumaa, Vormsi and Muhumaa) and western continental coast. The second PC represents the southeastern region of the country. The third PC represents the northern coast.

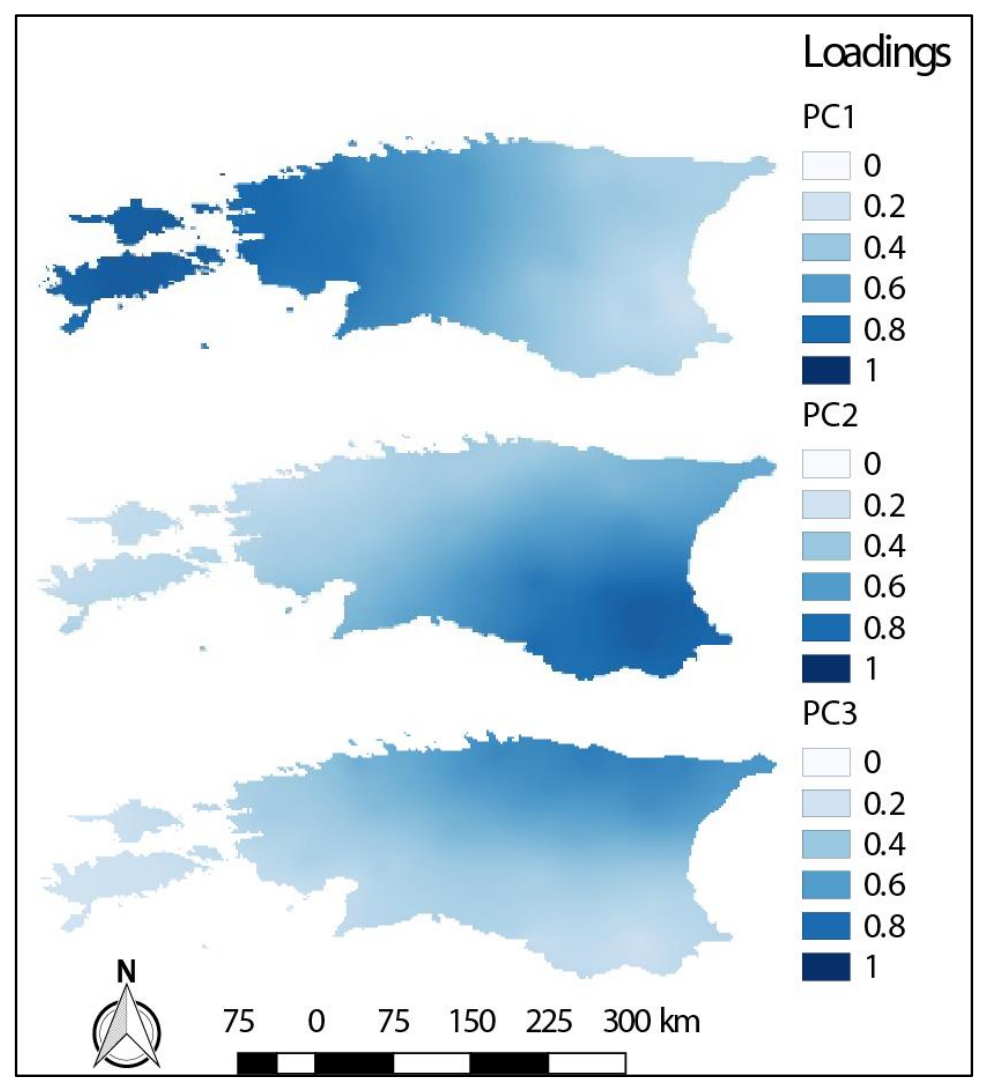

Figure 2. Spatial distribution of loadings from PCA.

\subsection{General overview of droughts}

The country-scale SPI (Figure 3) shows a mainly dry period from 1951 to 1977 only interrupted by some months with low positive values; the most severe drought during this period is from August 1962 to September 1966. From 1978 to 2015 wet conditions prevail however some severe short droughts occurred during this period.

These main features are recognizable in the three regional series. Nevertheless important differences appear if we analyze the series in detail e.g. the drought of 2003 is considerably more intense in the western region than in the southeastern and northern. On the other hand, the 2006 droght is more intense in the northern region. 
The 1st International Electronic Conference on Hydrological Cycle (CHyCle-2017), 12 - 16 November 2017; Sciforum Electronic Conference Series, Vol. 1, 2017
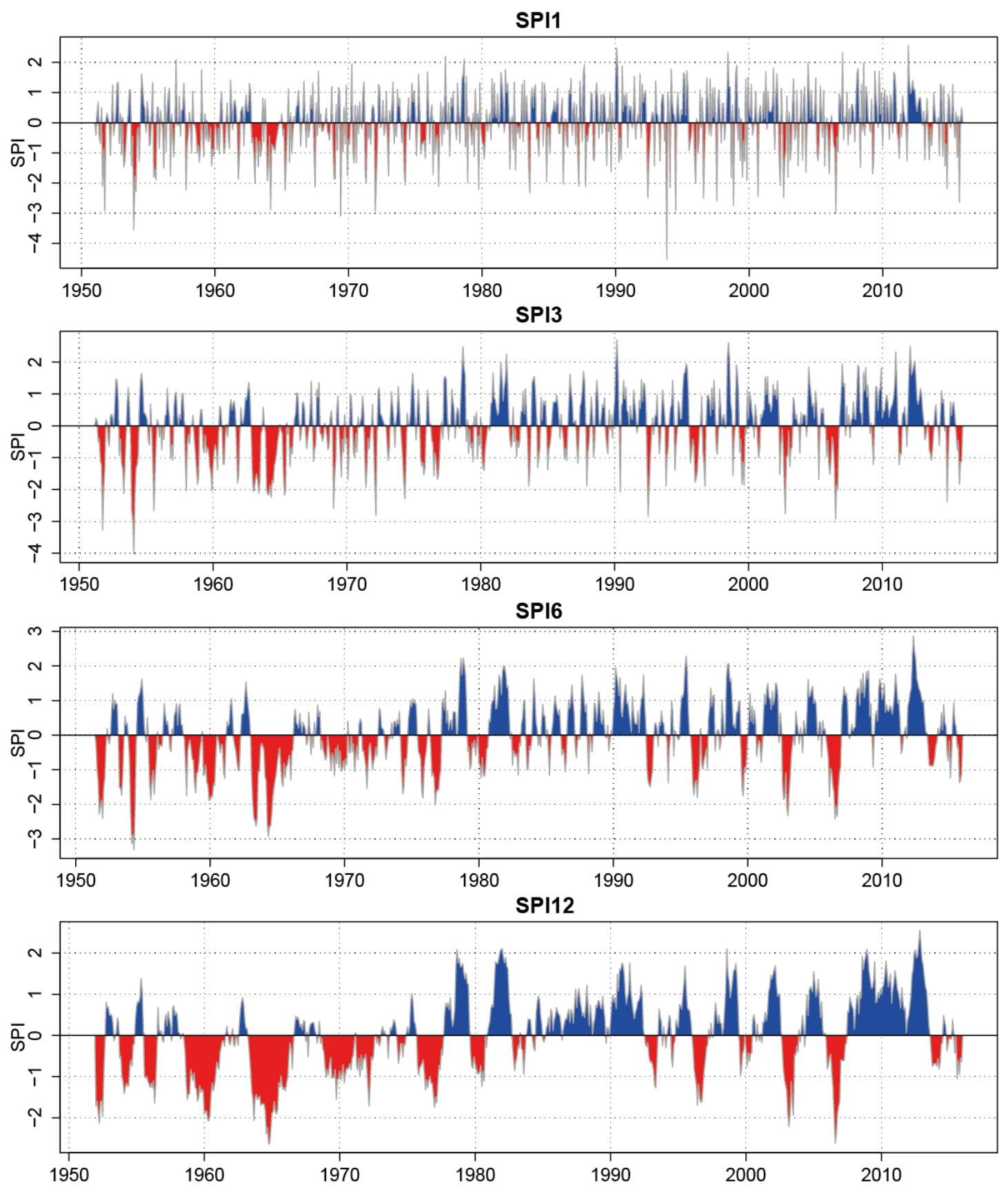

Figure 3. Evolution of country-scale 1, 3, 6 and 12 months SPI time series.

\subsection{Influence of atmospheric indices on drought variability}

Table 1 shows seasonal Pearson's correlation coefficient between country-scale SPI and the atmospheric indices. Spring droughts have the lowest correlation coefficient and it is only significant with EATL/WRP (negative) and SCAND (negative). On the other hand, summer droughts show significant correlations with all the indices studied. SCAND shows significant correlations in all the seasons and it is the index with highest correlation during spring and autumn. NAO shows significant correlation during winter and summer but the strongest correlation during these seasons 
The 1st International Electronic Conference on Hydrological Cycle (CHyCle-2017), 12 - 16 November 2017;

Sciforum Electronic Conference Series, Vol. 1, 2017

is with WI. Figure 4 shows the correlation coefficient at station scale between SPI and the most correlated index i.e. SCAND (spring and autumn), WI (summer and winter). During spring some stations in the northern and southeastern region have no significant correlation. During winter only one station (southeastern region) has no significant correlation. However during summer and autumn all the stations have significant correlation.

Table 1. Pearson's correlation coefficient between seasonal SPI and atmospheric indices. Values in bold are statistically significant at the $95 \%$ confidence level.

\begin{tabular}{cccccccc}
\hline & EA & EATL/WRUS & P/EU & SCAND & NAO & AO & WI \\
\hline Winter & 0.220 & -0.055 & $\mathbf{- 0 . 3 2 4}$ & $\mathbf{- 0 . 4 6 5}$ & $\mathbf{0 . 4 1 7}$ & $\mathbf{0 . 3 5 8}$ & $\mathbf{0 . 5 0 8}$ \\
\hline Spring & 0.184 & $\mathbf{- 0 . 2 4 6}$ & -0.180 & $\mathbf{- 0 . 3 3 5}$ & -0.069 & 0.057 & 0.237 \\
\hline Summer & $\mathbf{0 . 2 8 9}$ & $\mathbf{- 0 . 4 3 8}$ & $\mathbf{- 0 . 4 0 6}$ & $\mathbf{- 0 . 3 3 6}$ & $\mathbf{- 0 . 4 5 6}$ & $\mathbf{- 0 . 3 0 4}$ & $\mathbf{0 . 5 9 0}$ \\
\hline Autumn & -0.032 & $\mathbf{- 0 . 2 6 7}$ & -0.132 & $\mathbf{- 0 . 6 0 5}$ & -0.205 & 0.049 & $\mathbf{0 . 3 7 9}$ \\
\hline
\end{tabular}

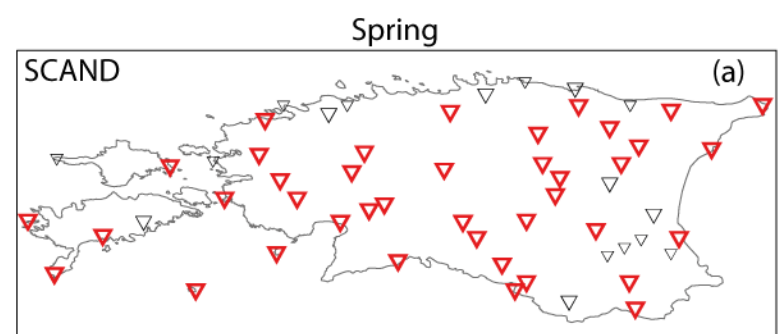

Autumn

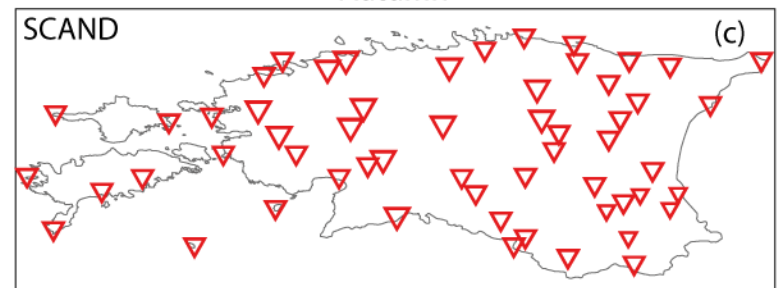

$0.6>\triangle 0.6 \triangle 0.4 \triangle 0.2$

Summer

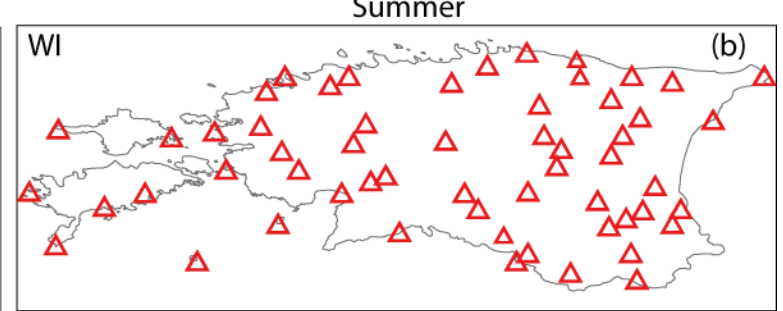

Winter

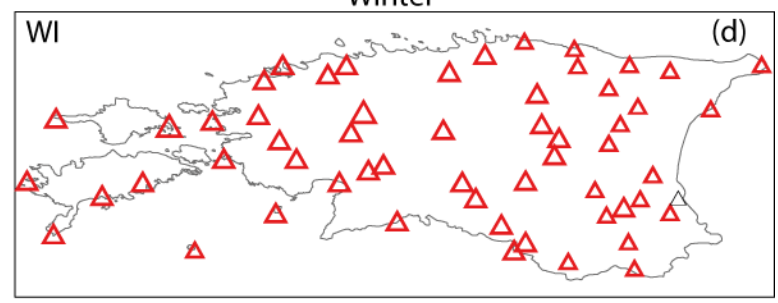

$0 \quad \nabla-0.2 \nabla-0.4 \nabla-0.6 \nabla-0.6<$

Figure 4. Pearson's correlation coefficient between: (a) spring SPI and SCAND, (b) summer SPI and WI (c) autumn SPI and SCAND and (d) winter SPI and WI. Red triangles indicate correlation statistically significant at the $95 \%$ confidence level.

\section{Discussion and Conclusions}

This work shows, for the first time, the influence of the main circulation indices (NAO, EA, EATL/WRUS, SCAND, P/EU, AO and WI) on drought variability from 1951 to 2015 in Estonia. A clear change in drought patterns occurs around 1980 when droughts start to be shorter and less frequent. The 1960s was the driest decade although the most intense droughts occurred in 2003 and 2006. These main features of the drought variability in Estonia are also recognizable in Finland [8]. Although the most prominent index used to characterize the large scale atmospheric variability over northern Europe is NAO [3, 4, 14, 15] in Estonia the circulation indices with more influence in seasonal drought occurrence are WI (for winter and summer) and SCAND (for spring and autumn). NAO shows no significant correlation with SPI during spring and autumn and weaker correlations than WI in winter and spring. 
The 1st International Electronic Conference on Hydrological Cycle (CHyCle-2017), 12 - 16 November 2017; Sciforum Electronic Conference Series, Vol. 1, 2017

Acknowledgments: The authors want to thank the EU and Spanish Ministry of Economy and Competitiveness for funding within the framework of the collaborative international consortium IMDROFLOOD financed under the ERA-NET Cofound WaterWorks2014 Call, an integral part of the 2015 Joint Activities conducted by the Water Challenges for a Changing World Joint Programme.

Author Contributions: All the authors contributed equally to the manuscript.

Conflicts of Interest: The authors declare no conflict of interest.

\section{Abbreviations}

The following abbreviations are used in this manuscript:

NAO: North Atlantic Oscillation

EA: East Atlantic pattern

EATL/WRUS: East Atlantic/Western Russia pattern

SCAND: Scandinavian pattern

P/EU: Polar/ Eurasia

AO: Artic Oscillation

WI: Westerly Index

\section{References}

1. Tipping E., Smith E.J, Lawlor A.J., Hughes S., Stevebs P.A. Predicting the release of metals from ombrotrophic peat due to drought-induced acidification. Environmental Pollution 2003,123, 239-253.

2. Saarinen T., Vuori K., Alasaarela E., Klove B. Long-term trends and variation of acidity, CODMn and colour in coastal rivers of Western Finland in relation to climate and hydrology. Sci Total Environ 2010, 408, 50195027

3. López-Moreno, J. I.,Vicente-Serrano S.M. Positive and negative phases of the wintertime North Atlantic Oscillation and drought occurrence over Europe: A multitemporalscale approach. J. Climate, 2008, 21, 12201243.

4. $\quad$ Kingston D.G., Stagge J.H., Tallaksen L.M., Hannah D.M. 2015. European-scale drought: understanding connections between atmospheric circulation and meteorological drought indices. J. Clim. 2015, 28: 505516.

5. Vicente-Serrano S.M., García-Herrera R., Barriopedro D., Azorin-Molina C., López-Moreno J.I., MartínHernández N., Tomás-Burguera M., Gimeno L., Nieto R. The Westerly Index as complementary indicator of the North Atlantic oscillation in explaining drought variability across Europe. Climate Dynamics 2016, 47 (3-4), 845-863.

6. Vicente-Serrano S.M., López-Moreno J.I. The influence of atmospheric circulation at different spatial scales on winter drought variability through a semi-arid climatic gradient in northeast Spain. International Journal of Climatology 2006, 26 (11), 1427-1453.

7. Jaagus J. 2009. Regionalization of the precipitation pattern in the Baltic Sea drainage basin and its dependence on large-scale atmospheric circulation. Boreal Environ. Res. 2009, 14: 31-44.

8. Irannezhad, M., Ahmadi, B., Kløvea, B., Moradkhani, H. Atmospheric circulation patterns explaining climatological drought dynamics in the boreal environment of Finland, 1962-2011. Int. J. Climatol. 2017, 37, 801-817.

9. Venema V.K.C., Mestre O., Aguilar E. et al. Benchmarking homogenization algorithms for monthly data. Climate of the Past 2012, 8, 89-115.

10. Mestre O., Domonkos P., Picard F., et al. HOMER: a homogenization software- methods and applications. IDÖJÁRÁS Quarterly Journal of the Hungarian Meteorological Service 2013, 117(1).

11. Barnston A.G., Livezey R.E.. Classification, seasonality and persistence of low-frequency atmospheric circulation patterns. Monthly weather review 1987, 115(6), 1083-1126.

12. Barriopedro D., Gallego D., Álvarez-Castro M.C., García-Herrera R., Wheeler D., Peña-Ortiz C., Barbosa S.M. Witnessing North Atlantic westerlies variability from ships' logbooks (1685-2008). Clim. Dyn. 2014, 43, 939-955. 
The 1st International Electronic Conference on Hydrological Cycle (CHyCle-2017), 12 - 16 November 2017;

Sciforum Electronic Conference Series, Vol. 1, 2017

13. McKee T.B.N., Doesken J., Kleist J. The relationship of drought frequency and duration to time scale, Proceedings of the Eighth Conference on Applied Climatology, Anaheim, California, 17-22 January 1993.

14. van der Schrier G., Briffa K.R., Jones P.D., Osborn T.J. Summer moisture variability across Europe. J. Climate 2006, 19, 2828-2834.

15. Sousa PM et al. Trends and extremes of drought indices throughout the 20th century in the Mediterranean. Natural Hazards and Earth System Science 2011, 11, 33-51.

(C) 2017 by the authors; licensee MDPI, Basel, Switzerland. This article is an open access article distributed under the terms and conditions of the Creative Commons by Attribution (CC-BY) license (http://creativecommons.org/licenses/by/4.0/). 